$\mathrm{AB} 0374$

NONTUBERCULOUS MYCOBACTERIUM INFECTIONS IN PATIENTS WITH RHEUMATOID ARTHRITIS: A SINGLECENTRE EXPERIENCE IN JAPAN

M. Hayashi, K. Funamura, M. Maeda, T. Kanamono. Departments Of Orthopedics Surgery And Rheumatology, Nagano Red Cross Hospital, Nagano, Japan

Background:

Objectives: Nontuberculous mycobacteria (NTM) infection has been increasing in both general population and immunocompromised patients in Japan. This study aimed to identify the incidence and clinical characteristics of NTM infections in patients with rheumatoid arthritis (RA).

Methods: We performed a cross-sectional analysis and assessed 11 RA patients, who were all female, complicated with NTM (mean age, 66.6 years) at our institute. We examined Steinbrocker Stage and Class, disease duration, positivity of anti-CCP antibody and rheumatoid factor, HAQ-DI, DAS28-ESR, NTM species, radiological features, methotrexate use and dosage, prednisolone use and dosage, biological agent use, and anti-NTM therapy.

Results: Average values obtained with SD were as follows: age (years), 66.6 \pm 8.0 ; Steinbrocker Stage I, 1; II, 0; III, 1; and IV, 9; Class 1, 2; 2, 5; 3, 4; and 4, 0;

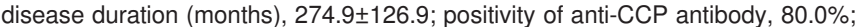
positivity of rheumatoid factor, 100\%; HAQ-DI, 1.35 \pm 0.72 ; DAS28-ESR, 3.61 \pm 0.90 ; detection by sputum culture, $81.8 \%$; NTM species, $M$. avium, 8 cases and M. intracellulare, 3 cases; bronchiectasis, $90.9 \%$; interstitial pneumonia, $0 \%$; methotrexate use and dosage (mg/week); $63.6 \%$ and $7.4 \pm 3.4$; prednisolone use and dosage (mg/day); $81.8 \%$ and $4.3 \pm 2.0$; biological agent use, $45.5 \%$; and antiNTM therapy, $36.4 \%$.

Conclusions: At our institute, RA patients complicated with NTM were longstanding, had high disease activities and worse HAQ-DI. In all five patients $(45.5 \%)$ who were treated with biologics, 3 who had preceding episodes of NTM infection were treated with anti-NTM therapy before treatment with biologics, and the other 2 who had asymptomatic NTM infection after treatment with biologics were not treated with anti-NTM therapy thereafter. In RA patients who are treated with biologics, it is necessary to perform sputum cultures constantly to detect possible NTM infections. This finding is important in the management of RA complicated with NTM.

Disclosure of Interest: None declared

DOI: 10.1136/annrheumdis-2018-eular.4383

\section{AB0375 A SYSTEMATIC LITERATURE REVIEW OF OMEGA 3 IN THE TREATMENT OF RHEUMATOID ARTHRITIS}

M. Prince ${ }^{1}$, M. Bukhari'. ${ }^{1}$ Lancaster Medical School, Lancaster University, ${ }^{2}$ Rheumatology, Royal Lancaster Infirmary, Lancaster, UK

Background: Many different elements and variations of diet in the management of rheumatoid arthritis (RA) have been studied over the years such as vegan or Mediterranean diets.

Objectives: This systematic literature review covers one food stuff, omega-3 polyunsaturated fats efficacy in the management of RA alongside or independent of conventional DMARD therapy.

Methods: A systematic review of the literature between 1966-2017 was conducted using MEDLINE, CINAHL and EMBASE databases, with key words "RA" and "omega-3" for English-language articles producing 209 hits. We then refined to publications within the last 10 years, giving 96 results. Only including clinical trials gave 12 hits pertaining to 8 trials.

Results: The table above shows a summary of the evidence found. In total, 751 were exposed to omega-3 versus 1733 controls with the smallest study being an
RCT involving 13 people and the largest a case-control study with 1569 participants. A notable difference between these studies was the use of DMARD therapy as part of the inclusion or exclusion criteria. Another difference noted was the RA stage eligible for a trial. Some studies required a diagnosis of RA of $<12$ months whereas most required stable RA ongoing for $>12$ months.

Conclusions: This review concludes that omega- 3 leads to clinical and statistically significant improvements in RA. There was a significant heterogeneity in the trials published with different inclusion criteria especially regarding disease duration and concomitant DMARD therapy. It would seem prudent to include dietary advice in our advice to patients when treating RA. Possible reasons for this evidence would include altering the microbiome.

\section{REFERENCES:}

[1] The British Journal of Nutrition 2015;114(6):885-90.

[2] Epidemiology 1996;7(3):256-63.

[3] Archives of Medical Research 2012;43(5):356-62.

[4] Journal of Parenteral and Enteral Nutrition 2010;34(2):151-5.

[5] Global Journal of Health Science 2015;8(7):18.

[6] Arthritis Care \& Research 2017.

[7] Rheumatology (Oxford, England) 2008;47(5):665-9.

[8] Nutrients 2017;9(4).

Disclosure of Interest: None declared

DOI: 10.1136/annrheumdis-2018-eular.3325

\section{AB0376 RAPAMYCIN INDUCES REMISSION IN PATIENTS WITH NEWLY DIAGNOSED RHEUMATOID ARTHRITIS}

M. Chen ${ }^{1}$, Z. Li ${ }^{1}$, H. Yao ${ }^{1}$, F. Hu ${ }^{1}$, J. Liang ${ }^{1}$, N. Yan ${ }^{1}$, H. Niu${ }^{1}$, C. Gao ${ }^{2}$, X. Li ${ }^{1}$, C. Wang ${ }^{1} .{ }^{1}$ Rheumatology, the Second Hospital of Shanxi Medical University, Taiyuan, China; ${ }^{2}$ Pathology, Brigham and Women's Hospital, Harvard Medical School, Boston, USA

Background: Rheumatoid arthritis (RA) is an autoimmune disease characterised by chronic inflammation of the joints. We found that there was an imbalance between Th17 and Treg cells in the patients with active refractory RA, reduced absolute number of Treg cells was found in these patients.

Objectives: To observe the medium-term curative effect of rapamycin in the treatment of 25 cases newly diagnosed rheumatoid arthritis.

Methods: Collecting 25 patients of newly diagnosed rheumatiod arthritis, which accorded with RA diagnosis standard of ACR in 1987. The patients were treated with rapamycin at a dose of $0.5 \mathrm{mg}$ every 2 days for 24 weeks, then we observed the change of clinical improvement and immunological assessments after 24 weeks.

Results: There was 25 patients enrolled. After rapamycin treatment for 24 weeks, the mean DAS28 of them was decreased from 5.36 [1.42] to 3.45 [1.29] $(p=0.001)$ The absolute number of Treg ${ }^{\mathrm{CD} 4+\mathrm{CD} 25+\mathrm{Foxp} 3+}$ cells significantly higher than baseline (30.24 [14.44],46.64 [27.54], $\mathrm{p}=0.025)$. The absolute number of Th17 cells was not significantly different $(6.40[4.46], 7.03[5.60], p>0.05)$, and the same as the ratio of Th17/Treg cells $(0.25[0.18], 0.19[0.16]), p>0.05)$. Meanwhile, the mean dose of prednisone was decreased form $11.25 \mathrm{mg} / \mathrm{d}$ to $9.6 \mathrm{mg} / \mathrm{d}$.

Conclusions: Rapamycin could induce the balance of Th17 cells and Treg cells, especially up-regulate the absolute number of Treg cells, thus induce remission in patients with newly diagnosed RA.

Disclosure of Interest: None declared

DOI: 10.1136/annrheumdis-2018-eular.4146 